\title{
Creating the multimedia project experience database
}

J.W. van Aalst

Origin IT Services, Department Business Communication

P.O.Box 3336, Utrecht NL-3502-GH, The Netherlands, tel.

+31302911200, fax. +312911211

email Jan-Willem.vanAalst@nl.origin-it.com

C.A.P.G. van der Mast

Delft University of Technology, Technical Mathematics and

Informatics, Department information Systems

P.O.Box 356, Delft NL-2600-AJ, The Netherlands, +31 152782549 , fax.+31 15 2786632, email C.A.P.G.VanderMast@is.twi.tudelft.nl

\begin{abstract}
In this paper we present experiences and results of an inductive case study to identify the most fundamental project problems that are specific to the field of multimedia, with the aim of designing a framework for an online accessible multimedia project experience database. To identify the problems, we conducted 32 interviews on about 25 multimedia experts, gathering their experiences and opinions about success factors, knowledge numbers, management, communication, meetings, infrastructure, tools, etcetera. The results of these sessions are used in the design of a multimedia experience database from which multimedia experts can learn.
\end{abstract}

\section{Keywords}

multimedia projects, experience databases, improving project control 


\section{INTRODUCTION}

The multimedia industry can be seen as a subset of the general IT-industry, the main difference being the incorporation of various new disciplines in multimedia project teams, and the use of new, innovative (and often unstable) technologies and development tools (Van Aalst \& Van der Mast, 1996). These two aspects often cause considerable difficulty in producing high-quality multimedia systems such as computer based trainings, electronic performance support systems, marketing and sales presentations and internet sites (often sales kiosks) (see for example Van der Mast (1995)).

During the last few years, we see a slow but steady maturing process in the IT industry with the advent of the RAD methodology and its subsidiaries. Such methods, combined with the increasing power of software and hardware, offers companies better ways of climbing up the Capability Maturity Model scale (Humphrey, 1989). However, this maturing process cannot yet be found in a widespread fashion in the multimedia industry (England \& Finney, 1996). Other than for example the film industry, where script writers comfortably work together with directors and video technicians (see for example Monaco, 1981), a graphical designer still does not communicate easily with a Java programmer, for example. Now that multimedia products are (rightfully) no longer the result of a team of programmers alone, there is need for a specific multimedia language or jargon, just as this has happened in the film industry. It will take several years for such a language to emerge (Laurel, 1993).

In the general IT-industry, various factors have been identified that cause problems during development projects (see Van Aalst \& Van der Mast, 1995):

1. Sociological problems, consisting of organisational issues and communicational issues;

2. Technological problems, meaning the availability of robust tools, knowledge about, and experience with these tools, and a good working environment.

3. Political issues, where higher-level stakes influence the development process of the product.

We have summarised these problems in the following model: 


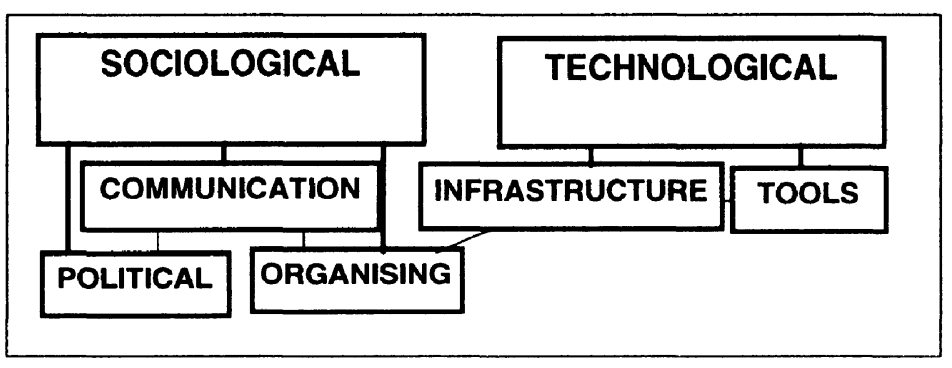

Figure 1 Project problems in IT-projects

These problems are found in the multimedia industry also. Still, it seems that there are also problems that are very specific to the multimedia industry. For example, the various disciplines do not communicate easily with eachother, and the HCI expert needs to communicate with virtually all disciplines. In this paper we identify these aspects and describe their role in the setup of an online accessible experience database to learn from past experiences with multimedia projects.

This paper is set up as follows. First, we describe the framework that we use to look at the area of multimedia project problems; then we describe the methods that we use to identify these problems; then, the actual experiment of identifying these problems and the setting up of the experience database is described. The paper then offers a brief discussion of the results, conclusions, and an overview of future research, as well as links to where more information about this research project can be found.

\section{FRAMEWORK}

An important way of improving an IT-product is to improve the way in which the project that leads to that product is organised; in other words, making sure there is sufficient control over that project at all times (improving control over the process). For the IT-industry, sophisticated 'planning \& control' tools are emerging, like QSM's SLIM (Greene (1996), and Putnam \& Myers (1996)) and Transform by SHL Systemhouse (Hughes, 1997). However, when examining such tools, we see that they do not yet support the specific nature of multimedia projects: they are still working too much from a computer-science point of view. For example, the tools described above can measure product size only in ELOC (effective lines of code), or in simple GUI units. In the multimedia industry, direct manipulation development tools are common; moreover, graphics, video and audio can be a substantial part of the total effort.

To adapt these tools to specific multimedia problems, one needs to have an overview of the experiences of multimedia experts, and their (interconnected) project problems, needs and wishes. To build that overview, we create, through interviewing sessions, a multimedia experience repository; a database that all multimedia experts can access 
and can learn from. Such a database contains project experiences of project managers, administrators, visual designers, specificators, programmers, etc., about multimedia project problems such as project management, communication, meetings, customer participation, technical infrastructure, working conditions, project pressure, etc, as well as multimedia-specific knowledge numbers. In other words, there is both a quantitative (knowledge numbers) and a qualitative (emotional experiences) side to it. We define the following roles, partly after (England \& Finney, 1996):

- project manager

- project administrator

- quality assurance manager

- art director

- graphic designer
- interaction designer

- video artist

- video engineer

- audio artist

- audio engineer

- domain expert
- designer

- specificator

- programmer 3gl

- programmer $4 \mathrm{gl}$

- tester

Multimedia experts can learn from each other's experiences using the experience database. For example, when setting up a project bid, a multimedia project manager can check which parts of such a bid have in previous years often been the cause of questions or trouble. Or, a project manager can check what percentage of the budget his colleagues have reserved for making a project bid, for previous projects. Or, a programmer can check what technical pitfalls he or she should be aware of when making a Java applet. Moreover, as the use of the database increases, it can also grow to a level to where it is a mirror of all project problems in multimedia projects.

To make the multimedia experience database work, there would need to be a cycle of multimedia projects making use of the database, while at the same time storing new data in de database. This cycle is described in figure 2 below.

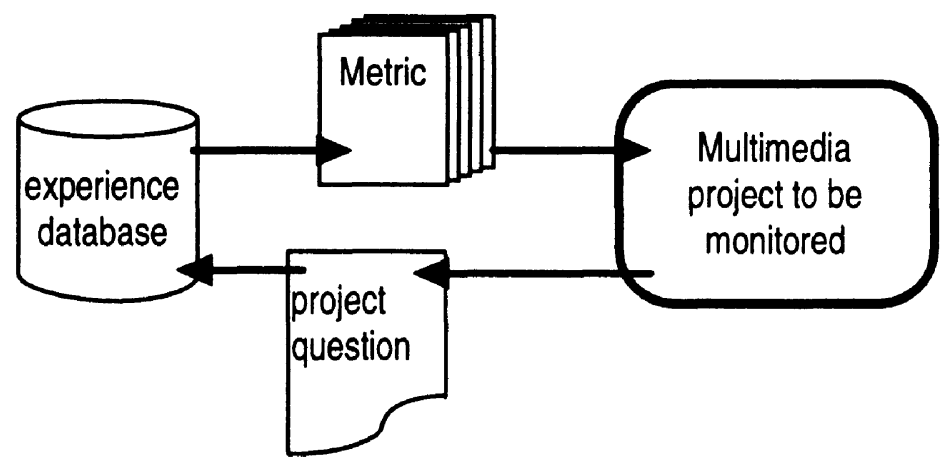

Figure 2 The global framework of improving control over multimedia-specific problems 
In this paper, we describe the use of the questionnaires to identify the multimedia specific project problems, their use in the design and realisation of the multimedia experience database, and the opinion of multimedia project members about the contents and usefulness of the database.

\section{METHOD AND EXPERIMENT}

The first phase in the process of setting up the cycle described in figure 2 has been realised. It consisted of an inductive case study of sixteen interviewing sessions with various multimedia experts An initial questionnaire was designed, with an estimation of problems that would probably arise; on top of that, the experts were stimulated to explain their own opinions about the most fundamental problems. After that, a second iteration of fourteen interviewing sessions was held. In tables $1.1-1.3$, we give a quantitative description of the interviewing sessions of the first iteration.

Table 1.1 Interview data for seven products

\begin{tabular}{|l|l|l|l|}
\hline Project type: & $\begin{array}{l}\text { Duration } \\
\text { (weeks) }\end{array}$ & Average \# staff & $\begin{array}{l}\text { \# } \\
\text { interviews }\end{array}$ \\
\hline CBTraining & 10 & 3 & 1 \\
\hline CBTraining & 12 & 6 & 5 \\
\hline CBTraining & 17 & 4 & 2 \\
\hline presentation & 24 & 6 & 2 \\
\hline presentation & 8 & 5 & 2 \\
\hline publishing & 20 & 5 & 2 \\
\hline EPSS & 23 & 3 & 2 \\
\hline
\end{tabular}

These are all multimedia products. CBT means Computer Based Training; EPSS means Electronic Performance Support System. Publishing means a kiosk application or other similar products. 
Table 1.2 Interviews held for each of the project member roles

\begin{tabular}{|l|l|}
\hline Role & \# int. \\
\hline Project managers & 6 \\
\hline Designers/content experts & 4 \\
\hline Graphic artists & 2 \\
\hline Programmers & 3 \\
\hline Testers & 1 \\
\hline
\end{tabular}

Table 1.3 Project phases in which the interviews were held

\begin{tabular}{|l|l|}
\hline Phase & \# int. \\
\hline planning phase & 6 \\
\hline design \& main build phase: & 6 \\
\hline evaluation phase & 4 \\
\hline
\end{tabular}

The answers we got from these interviewing sessions were used for the design of an improved version of the questionnaire. These questionnaires were more specifically aimed at capturing the multimedia project experience that could be useful for future multimedia projects. For each of the three main phases: project bid/startup, Main build, Evaluation (categorisation taken from Greene (1996)), and for each of the three main parties involved: project manager, project team, customer (categorisation taken from DeMarco \& Lister, 1987), we have designed a separate list of questions, equalling $3 * 3=9$ questionnaires. Furthermore, we have designed a project household questionnaire with some general data like staffing, billing, milestones, cost, effort, size, etc. Each questionnaire contains questions only for the specified role to be interviewed, during the specified phase. Guidelines for the construction of the latest version of the questionnaire were taken from the work by Oppenheim (1990).

From the results of the interviewing sessions, it became clear that we needed to capture especially the following problem categories:

- projects data and experience: billing, staffing, milestones, effort, cost, defects, management problems, communication problems, meetings, customer participation, technical infrastructure, working conditions, etc.;

- products data and experience: type, concepts, size, target audience descriptions, number of users, benefit for customer, media mix, platform, documentation; 
- critical success factors: financial/work issues, risk analysis, general reference;

- knowledge numbers: e.g. boundary conditions, influences and best-before-date;

- tips and tricks: for example about bugs in multimedia development tools.

We used this second version of the questionnaires in a second iteration of another fourteen interviewing sessions. In tables $2.1-2.3$, we give a quantitative description of the sessions of the second iteration.

Table 2.1 Interview data for eight products (second set of interview sessions)

\begin{tabular}{|l|l|l|l|}
\hline Product type: & Duration (weeks) & $\begin{array}{l}\text { Average } \\
\text { staff }\end{array}$ & \# interviews \\
\hline CB Training & 21 & 7 & 5 \\
\hline EPSS & 17 & 4 & 4 \\
\hline Intranet & 50 & 5 & 4 \\
\hline EPSS & 16 & 3 & 1 \\
\hline CB Training & 38 & 6 & 0 \\
\hline CB Training & 47 & 4 & 0 \\
\hline CB Training & 9 & 4 & 0 \\
\hline CB Training & 16 & 4 & 0 \\
\hline
\end{tabular}

(The data from the projects that were analysed for which no interviews were held, was taken from extensive archival documentation.)

Table 2.2 Interviews held for each of the project member roles

\begin{tabular}{|l|l|}
\hline Role & $\#$ int. \\
\hline Project managers & 4 \\
\hline Designers/content experts & 4 \\
\hline Graphic artists & 3 \\
\hline Programmers & 3 \\
\hline Testers & 0 \\
\hline
\end{tabular}


Table 2.3 Project phases in which the interviews were held

\begin{tabular}{|l|l|}
\hline Phase & \# int. \\
\hline planning phase & 4 \\
\hline design \& main build phase: & 6 \\
\hline evaluation phase & 4 \\
\hline
\end{tabular}

Table 3 The expert level of the multimedia project members that have been interviewed

\begin{tabular}{|l|l|}
\hline Level of experience & $\#$ \\
\hline Not experienced (novice) & 0 \\
\hline Slightly experienced $(1$ year $)$ & 2 \\
\hline Fairly experienced $(>3$ years $)$ & 9 \\
\hline Experienced $(>5$ years $)$ & 12 \\
\hline Highly experienced $(>10$ years $)$ & 2 \\
\hline
\end{tabular}

In all interviewing sessions, the following method was used:

1. Interviewer determines role of employee to be interviewed.

2. Interviewer determines the current phase in which the project is.

3. Interviewer and subject sit opposite each other in a closed room. Interviewer explains the nature of the interview and the eventual purpose of storage of the results.

4. Interviewer asks questions to subject; sometimes skips a question if it has been answered by a previous subject for the same project for the same phase.

5. Interviewer enters answers by the subject in digital form. Names are anonymised.

6. Digital results of interview are sent back to subject for final check.

7. After receiving final sign-off, the interviewer stores the results of the interview in the experience database.

We found that the most important multimedia specific problems can be summarised as follows (please compare to figure 1):

- Organisational: get the various disciplines to effectively co-operate; plan the various tasks for the different media to be realised; use knowledge numbers to do this; 
- Communicational: listen to the perspective of other disciplines (especially important for the $\mathrm{HCI}$ expert); designing what needs to be communicated with the product;

- Technological: unstable tools, rapid changes in the software market (development tools), rapid changes in available technologies;

- Managing user's expectations: customers often are not able to estimate the technical feasibility/difficulty of their wishes and do not realise what a multimedia product approximately costs.

From the interviewing results, we designed a simple entity-relationship diagram as the basis for the multimedia experience database.

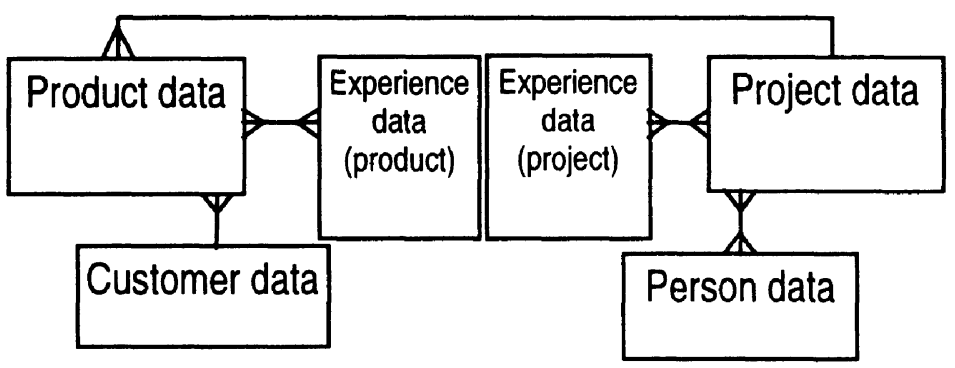

Figure 3 Entity-Relationship diagram for the multimedia experience database

This diagram has resulted in fifteen physical tables, plus eleven tables listing the various enumerations that people can choose from, such as billing, project phases, product types, target audience, codes size units, etc. The advantage of such predefined enumerations is that experience entries can later be more easily compared (for example find all projects that have resulted in the same product type).

The available tables are:

- product

- product size

- customer

- tips and tricks

- product experience
- project

- project problems

- project experience

- team

- defects
- cost

- effort

- mm experience descr.

- milestones

- person

The quantitative experience about communication, meetings, customer participation, etcetera, is stored into the project problems table, while the success factors and knowledge numbers are stored in the project experience table. 


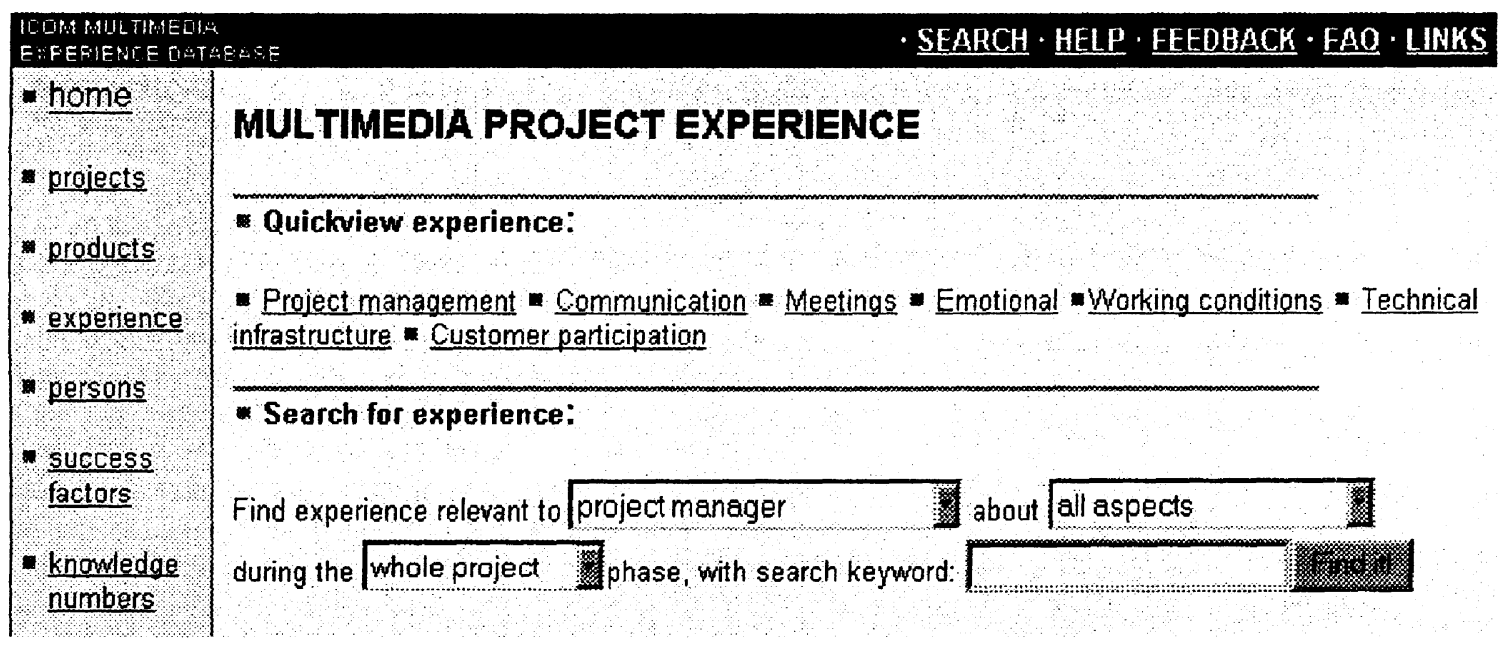

Figure 4 Part of screen from the online accessible multimedia experience database

We wanted to offer the multimedia project team members and project managers the possibility of querying the database online, through a web browser, so that they could learn from the experience entered by others during the interviews. The database was in Access format, and we used Frontpage to set up a web site on a Windows-NT 4.0 server with the IIS $/ 3.0$ web server. Later we constructed a more advanced, open query in which various parameters as well as a freely choosable keyword could be entered, shown in figure 4 . In this search, one can ask for project experiences relevant to a project manager, about communication, or meetings, technical infrastructure, etc., for a particular project phase, with a search keyword.

\section{DISCUSSION}

Here are some samples from the project interviews, taken directly from the experience database:

- "Problems with keeping the project organised? hm, firstly, there were a great many parties each with their own interests, resulting in white noise in communication and thus producing inefficiency in the project process. Secondly, there was no dedicated content-material expert on the project. Thirdly, there was a large geographical distance between the production team and the customer's headquarters."

- "It would have been better if there had been more formal communication; the value of that decreased because there was little formal communication anymore. 
But the schedule was so tight that there was barely any time left for formal communication"

- "The office space in itself was okay, but we were there together with the customer, which resulted in two groups in one room. It wasn't bothersome, but we lacked spontaneity a bit.".

- "The customer sticks firmly to their own opinion. And sometimes they really do have good arguments, and then it's difficult to convince them of something we think is better. Really difficult, I mean."

- Numbers of estimated overhead per week on: insufficient communication between disciplines (4), insufficient technical infrastructure (8), insufficient $\mathrm{HCI}$ expertise available (2), lack of one person with several disciplines (2), and poor concepts and content (2).

One notable point is that all 25 multimedia experts are very enthusiastic about the interviewing sessions; they were all willing to take the time for the interview. Some of them remarked that even by just talking and actively thinking about these problems, you gain more insight into what went wrong. When we first showed them the experience database, all convinced that it is a crucial step in lifting the multimedia project process to a higher level. Of course, the usefulness of the experience database largely depends on the quality of the content.

\section{CONCLUSION}

The most important project problems that are specific to multimedia are:

- Get the various disciplines to effectively co-operate; plan the various tasks for the different media to be realised; use knowledge numbers to do this (organisational);

- Listen to the perspective of other disciplines (especially important for the HCI expert); designing what needs to be communicated (communicational);

- Unstable tools, rapid changes in the software market (development tools), rapid changes in available technologies (technological);

- Customers often are not able to estimate technical feasibility/difficulty, and do not realise what a multimedia product costs (managing user's expectations).

These problems can partly be solved by offering a multimedia experience database, where multimedia experts can learn from experiences of the past. The current set-up of the multimedia experience database, in combination with the multimedia project questionnaires, forms a solid basis for realising the cycle described in this paper for improving control over multimedia projects. 


\section{FUTURE RESEARCH}

A problem with the sharing of all this knowledge is that the multimedia experience has been delivered by over thirty multimedia experts from one and the same company. The information is therefore seen as somewhat 'company confidential', and has been restricted to within the firewall of the company (about 16,000 people worldwide). The database should be accessible anywhere on the world wide web. This functionality is potentially there, but needs to be unlocked by the firewall.

Since many of the experience that is stored has a qualitative character, it is hard to compare data entries and set up a way in which these properties can be objectively measured and improved. However, many of the qualitative experiences have been categorised into various subjects, and this in itself already provides a useful 'quantization'. The main goal of the further research is to investigate ways to set up a (quantitative) metric that makes use of the qualitative experience data, and thus builds up an extensive record of why things went wrong in multimedia projects, and how we can avoid these errors in later projects.

More about this research project can be found at http://is.twi.tudelft.nl/ jwva/, section ICOM (Improving Control Over Multimedia projects).

\section{ACKNOWLEDGMENTS}

We would like to express our sincere thanks to the following people that are directly involved in the ICOM research project: Toon Witkam, research coordinator at Origin; Johan Vader, Marcel Theunissen and Johan Versendaal, of Origin; prof. Jan Dietz at Delft University of Technology; and Jenny Preece and Tom Carey, for helpful comments in the course of the ICOM projects.

\section{REFERENCES}

Brooks, F.P. Jr. (1995) The mythical man-month. Essays on software engineering. Addison-Wesley, Reading, MA.

DeMarco, T., and Lister, D. (1987) Peopleware: productive projects and teams. Dorset House, U.K. 
England, E., and Finney, A. (1996) Managing multimedia. Addison-Wesley, Reading, MA.

Greene, J. (1996) Management measures for excellence: the software control office. QSM Ltd., U.S.

Hughes, J. (1997) A process management environment. Available at www.shl.com/ 103e7a.html. SHL Systemhouse.

Humphrey, W. (1989) Managing the Software Engineering process. Addison-Wesley, Reading, MA.

Laurel, B. (1993) Computers as theatre. Addison-Wesley, Reading, MA.

Monaco, J. (1981) How to read a film. The art, technology, language, history and theory of film and media. Oxford university press, New York.

Oppenheim, A.N. (1990) Questionnaire design, interviewing and attitude measurement. Pinter publishers (revised edition).

Putnam, L.H., and Myers, W. (1996) Controlling software development. IEEE Computer society press, Los Alamitos, CA.

Van Aalst, J.W., and Van der Mast, C.A.P.G. (1996) Analysis of problems during multimedia development projects. In A. Verbraeck (Ed.) Euromedia'96 Conference Proceedings, SCS, London, pp. 78-82

Charles van der Mast (1995) Professional Development of Multimedia Courseware". In Machine-Mediated Learning, 5 (3 \& 4), 269-292.

\section{BIOGRAPHY}

Jan-Willem van Aalst works as a multimedia interaction designer at Origin IT Services in The Netherlands. He is doing a part-time research project on improving control over large multimedia projects, using a multimedia project experience database and a project metric with which to measure multimedia projects.

Charles van der Mast is a senior researcher and associate professor at Delft University of Technology. His research topics include human-computer interaction, user interface design, computer based training, and virtual reality. He has published his Ph.D. thesis about developing educational software in 1995. 